\title{
Erratum to: Effectiveness Analysis of a Two Non-Identical Unit Standby System with Switching Device and Proviso of Rest
}

\author{
Darpandeep Kour \\ Department of Statistics, \\ University of Jammu, Jammu-180006, India. \\ Corresponding author: darpandeep25@gmail.com \\ J. P. Singh Joorel \\ Department of Statistics, \\ University of Jammu, Jammu-180006, India. \\ E-mail: jpsjoorel@gmail.com

\section{Neha Sharma} \\ Department of Statistics, \\ University of Jammu, Jammu-180006, India. \\ E-mail: nehasharma131091@gmail.com
}

Erratum to: International Journal of Mathematical, Engineering and Management Sciences, 4(6), 1496-1507, 2019. https://dx.doi.org/10.33889/IJMEMS.2019.4.6-118.

The Figure 6, Figure 7, Figure 8 and Figure 9 is being replaced with the following figures:

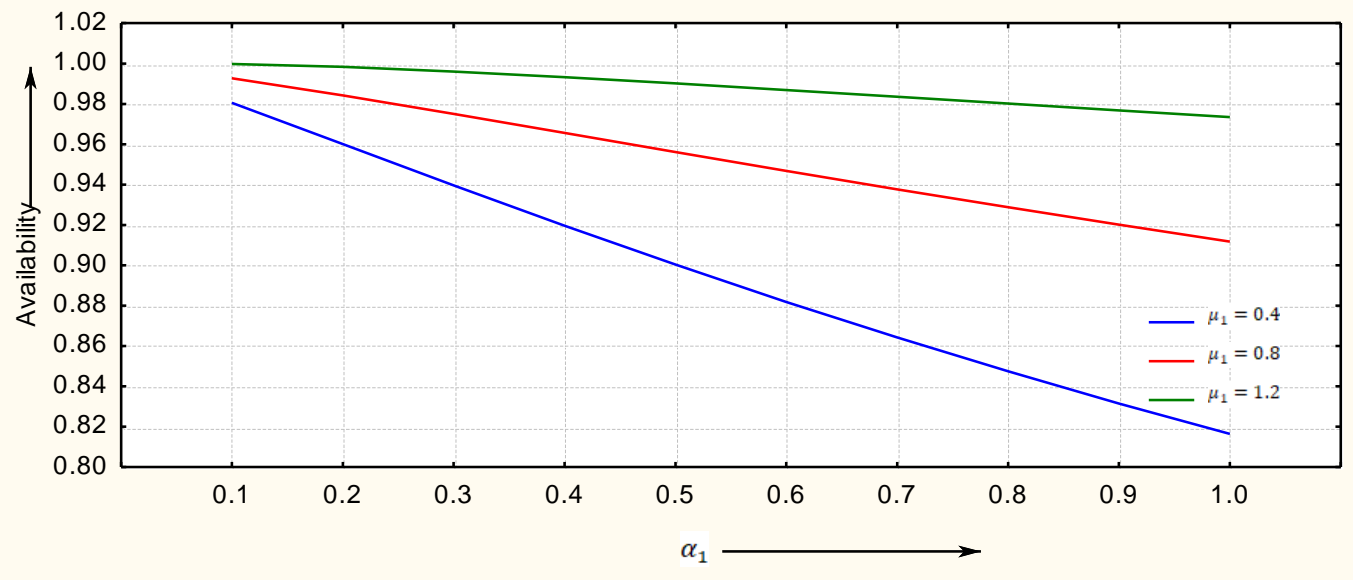

Figure 6. Behaviour of availability w.r.t. $\alpha_{1}$ for different values of $\mu_{1}$ 
International Journal of Mathematical, Engineering and Management Sciences

Vol. 5, No. 2, 378-380, 2020

https://doi.org/10.33889/IJMEMS.2020.5.2.031

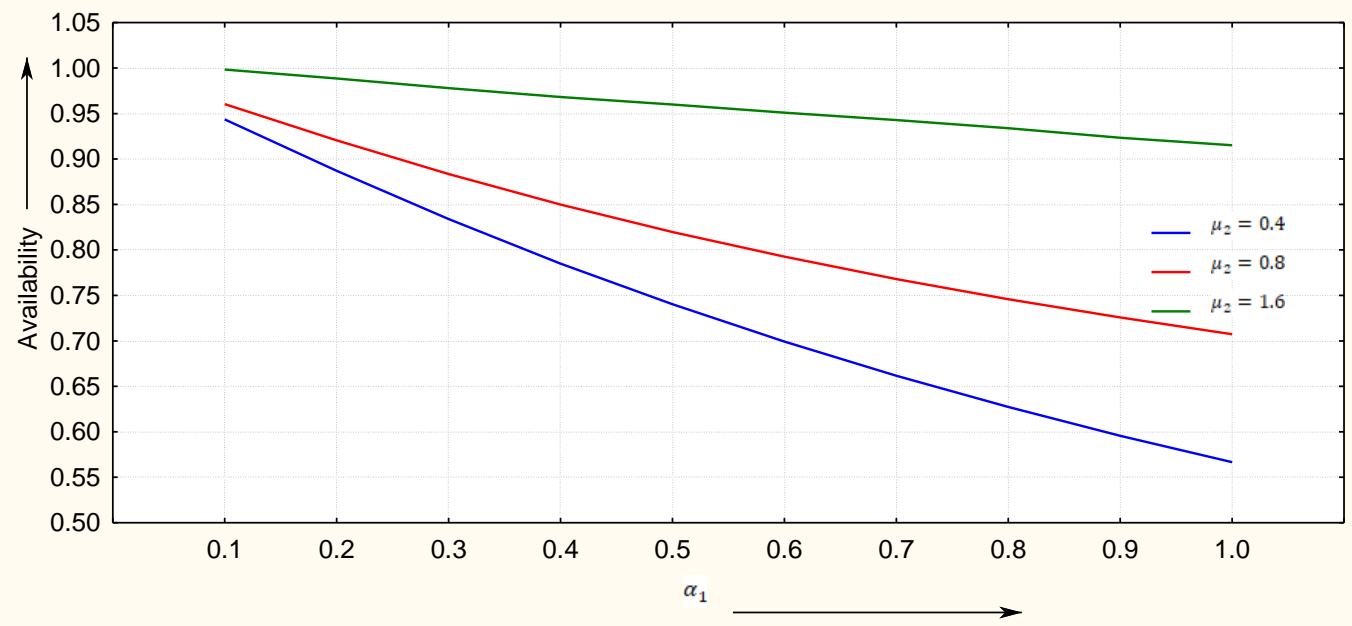

Figure 7. Behaviour of availability w.r.t. $\alpha_{1}$ for different values of $\mu_{2}$

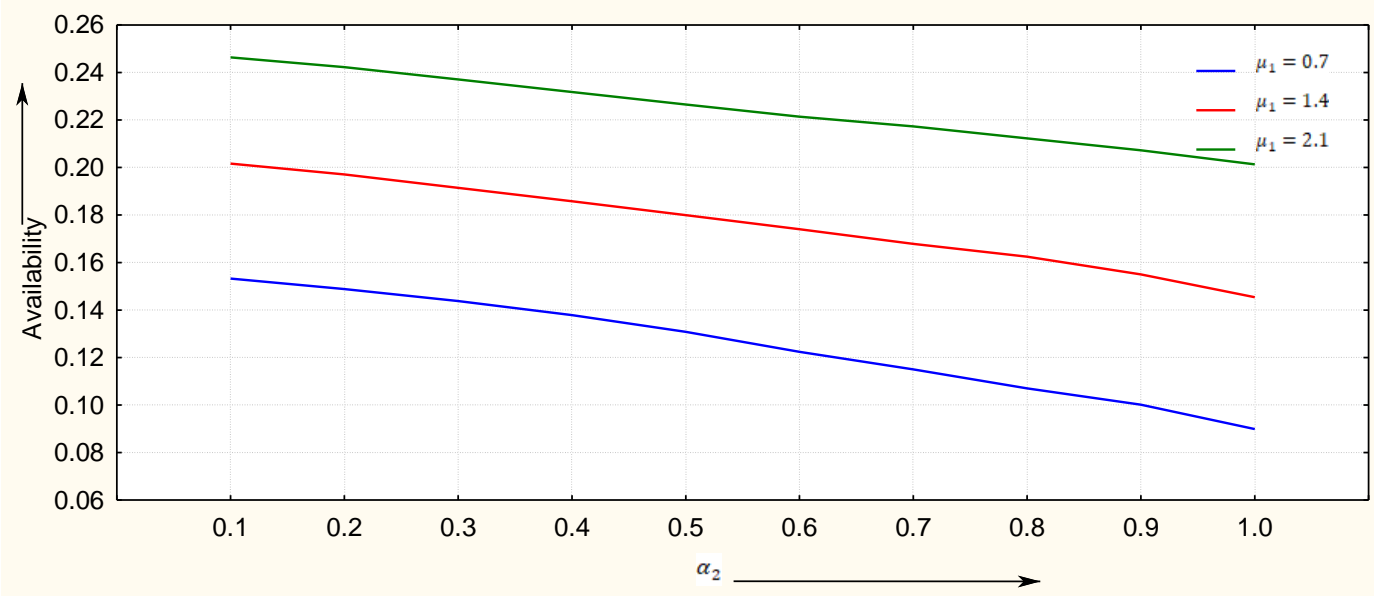

Figure 8. Behaviour of availability w.r.t. $\alpha_{2}$ for different values of $\mu_{1}$ 
International Journal of Mathematical, Engineering and Management Sciences

Vol. 5, No. 2, 378-380, 2020

https://doi.org/10.33889/IJMEMS.2020.5.2.031

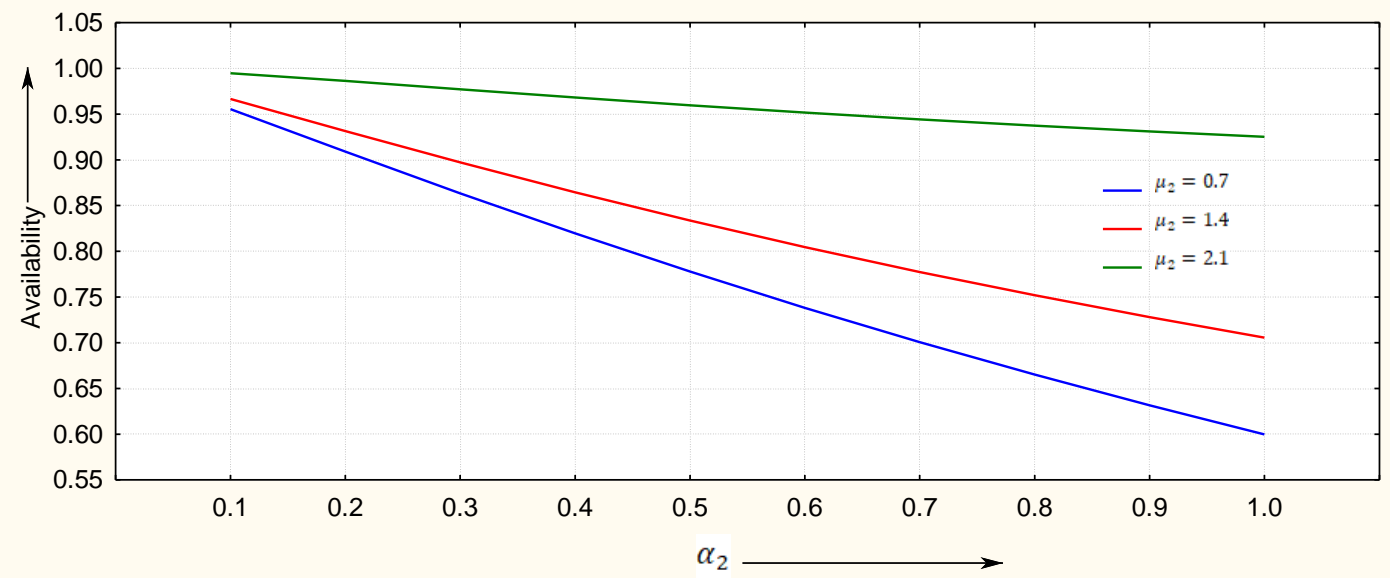

Figure 9. Behaviour of availability w.r.t. $\alpha_{2}$ for different values of $\mu_{2}$ 